\title{
New Advances in Gold Catalysis Part I*
}

\author{
David Thompson \\ $\overline{\text { Consultant to World Gold Council and Technical Editor, Gold Bulletin }}$ \\ Newlands', The Village, Whitchurch Hill, Reading, RG8 7PN, UK
}

\begin{abstract}
As for many aspects of gold science and technology, gold catalysis has unique features. Until recently, gold catalysis has had an uncertain history, but research work in a number of laboratories has now shown that if care is taken in the preparation of well defined supported gold systems then these systems can be unusually active and/or selective for a number of reactions of commercial importance. These include both selective and complete oxidation, hydrochlorination and hydrogenation reactions. In fact gold has been demonstrated to be the element of choice for some catalytic reactions. As a result, both chemical processing and environmental applications are foreseen for supported gold catalyst systems. In this, the first of two articles, the current knowledge on the hydrochlorination of ethyne and the low temperature oxidation of carbon monoxide using supported gold catalysts is reviewed. In the second part, some further examples of heterogeneous catalysis will be given and the importance of some recently reported early examples of homogeneous gold catalysis, in solution, assessed.
\end{abstract}

Since the beginning of 1996 Gold Bulletin has reviewed the current status of gold science and technology in most of its principal areas of application, including metallurgy and jewellery; pharmaceuticals and dentistry; chemistry and catalysis; analytical methods; and electronics and electrochemistry, plating and electrocatalysis. We should also include the use of gold for decoration of ceramic tableware and decorative plates. A striking outcome of all these recent articles is the emergence of a common theme, ie the unique nature of the properties of gold and its derivatives. A summary of the properties of gold in relation to its applications is given in Figure 1 (1). The uniqueness of gold can be rationalized in terms of its relativistic contraction - Figure 2 demonstrates the "relativistic contraction' for the $6 s$ orbitals of the heavy elements as a function of the atomic number $Z$. The element gold $(\mathrm{Z}=79)$ is at a pronounced local minimum. Electrons in atoms with high atomic numbers are influenced by the increased nuclear point charge and reach speeds which are approaching the velocity of light, and therefore must be treated according to Einstein's theory of relativity $(1,2)$. This relativistic effect consists of three components, ie s-orbital and, to a smaller extent, $p$-orbital contraction, spin orbit coupling, and f-orbital expansion. The unique yellow colour of gold derives from the relativistic effect. The Van der Waals interactions between gold atoms are correlation effects.
Pyykko had predicted gold - rare gas chemical bonds before a compound containing $\mathrm{Au}-\mathrm{Xe}$ bonds had been prepared (3). The $\mathrm{Au}^{+}$ion is not noble in a classical sense - it is reactive, especially in the gas phase.

Professor Peter Schwerdtfeger has indicated the many apparent anomalies in the physical properties of gold compared with those of the other elements of Group 11 (IB), ie silver and copper, including colour, specific resistivity, electrical heat capacity, melting point and boiling point. Whereas the predominant oxidation states for copper are $\mathrm{Cu}(\mathrm{I})$ and $\mathrm{Cu}(\mathrm{II})$, and $\mathrm{Ag}(\mathrm{I})$ predominates for silver, $\mathrm{Au}(\mathrm{I})$ and $\mathrm{Au}(\mathrm{III})$ are the most stable for gold. There is good agreement between the various methods for calculating the relativistic bond contraction in $\mathrm{Au}_{2}$. Relativistic effects lead to increased Van der Waals interaction and increased physisorption energies on gold surfaces. In a recent paper (4), the structures of $\mathrm{AuX}_{3}$ and $\mathrm{Au}_{2} \mathrm{X}_{6}$ have been rationalized.

In addition, it is noticeable that most areas of gold science are at an earlier stage of evolution than that already attained for neighbouring elements in the Periodic Table, and although some of the potential

\footnotetext{
* The material for this article was the basis for the first part of a talk presented at the IPMI Annual Meeting in Toronto, 17 June 1998 and will be published as part of the Precious Metals 1998 'Proceedings of the Conference held in Toronto, Ontario, Canada'.
} 


\begin{tabular}{|c|c|c|}
\hline \multicolumn{3}{|c|}{ Unique Nature of Gold Science and Technology } \\
\hline Field & Characteristics & Applications \\
\hline METALLURGY & Incorruptible & $\begin{array}{l}\text { Jewellery } \\
\text { Electronics } \\
\text { Dentistry }\end{array}$ \\
\hline CHEMISTRY & $\mathrm{Au}(\mathrm{I}), \mathrm{Au}(\mathrm{III})$ dominant & $\begin{array}{l}\text { Liquid Crystals } \\
\text { MOCVD } \\
\text { Luminescence }\end{array}$ \\
\hline MEDICINE & Gold-protein interaction & $\begin{array}{l}\text { Arthritis treatment } \\
\text { Chemotherapy }\end{array}$ \\
\hline ELECTROCHEMISTRY & $\begin{array}{l}\text { Oxide deposits on } \\
\text { surface of metal }\end{array}$ & $\begin{array}{l}\text { Active state for gold } \\
\text { eletrocatalysis } \\
\text { Plating } \\
\text { Electroforming }\end{array}$ \\
\hline CATALYSIS & Special & Topic of this Report \\
\hline
\end{tabular}

Figure 1 Examples illustrating the applications of gold and its derivatives in relation to its properties



Figure 2 Relativistic contraction' $\left(r_{\text {ref }} / r_{\text {nontel }}\right)$ for the 6s orbitals of the heavy elements as a function of the atomic number $Z$. Gold $(Z=79)$ represents a pronounced local minimum (based on reference 1)

applications are at an early stage of development, many significant developments can be anticipated in the future.

Whereas in earlier studies gold had been regarded as a useful promoter in some catalytic reactions, it has now been demonstrated that in some circumstances supported gold catalyst systems themselves can be the most active, and this has been rationalized via theoretical concepts. That gold systems are best for some reactions has been demonstrated both in the synthesis of vinyl chloride from acetylene and in the low temperature oxidation of carbon monoxide.

The methods used to prepare gold catalysts are critically important and for example co-precipitation is superior to impregnation, the method widely used for preparing platinum group metal catalysts. Recent results indicate that further investigation could lead to new applications for gold catalyst systems in both the chemical processing and environmental fields. Although much more research is required in order to identify and realize the full potential of the catalysts studied to date, use in such important areas of application as fuel cells and some forms of vehicle pollution control can be foreseen as possibilities, as well as in masks for removing toxic gases such as carbon monoxide.

Initial results in both homogeneous and supported homogeneous catalysis indicate that the field of gold catalysis as a whole is beginning to progress and is worthy of closer examination. Increased funding for research into gold catalysis would be likely to produce new applications. Parallels can be drawn with the growing numbers of applications for platinum metals catalysis achieved in the recent past, and it is reasonable to speculate that a significant proportion of gold sales could in due course be for catalyst manufacture.

\section{PLATINUM USAGE COMPARED WITH THAT FOR GOLD}

In Figure 3 the marketing position for platinum is indicated in terms of annual demand in 1975 and 1997. It can be seen that there have been significant changes in the spectrum of uses.

With the exception of the traditional area of metallurgy, most of the other areas of gold science and technology are very underdeveloped. When more is known about the technical capabilities of gold derivatives the spectrum of uses for this metal could also change. A knowledge of gold metallurgy has been well advanced for many centuries, as for example is evident for the historical articles we publish in Gold Bulletin. This knowledge has led to the current wide use of gold and its alloys in jewellery. It is not surprising therefore that the predominant industrial use for gold is in the manufacture of jewellery and this currently dwarfs all other applications as is indicated in

\begin{tabular}{|c|c|c|c|}
\hline \multicolumn{4}{|c|}{ Platinum Usage - 1975 and 1997 ('000 oz) } \\
\hline \multicolumn{2}{|c|}{ DEMAND BYAPPLICATION } & 1975 & 1997 \\
\hline \multirow{2}{*}{\multicolumn{2}{|c|}{$\begin{array}{l}\text { Autocatalyst: gross } \\
\text { recovery }\end{array}$}} & 360 & 1,840 \\
\hline & & 0 & (370) \\
\hline \multicolumn{2}{|l|}{ Chemical } & 345 & 235 \\
\hline \multicolumn{2}{|l|}{ Electrical } & 225 & 305 \\
\hline \multicolumn{2}{|l|}{ Glass } & 65 & 275 \\
\hline \multirow[t]{2}{*}{ Investment } & small & 0 & 180 \\
\hline & large & 0 & 110 \\
\hline \multicolumn{2}{|l|}{ Jewellery } & 1,210 & 2,160 \\
\hline \multicolumn{2}{|l|}{ Petroleum } & 165 & 170 \\
\hline \multicolumn{2}{|l|}{ Other } & 210 & 295 \\
\hline \multicolumn{2}{|c|}{ TOTAL DEMAND } & 2,580 & 5,200 \\
\hline
\end{tabular}

Figure 3 A comparison of platinum usage between 1975 and 1995. Source: Platinum 1998', Johnson Matthey plc, May 1998, and private communication 


\begin{tabular}{|c|c|c|}
\hline \multicolumn{3}{|c|}{ Gold Usage 1997 (tonnes) } \\
\hline \multirow{2}{*}{\multicolumn{3}{|c|}{$\begin{array}{l}\text { DEMAND BY APPLICATION } \\
\text { Fabrication: }\end{array}$}} \\
\hline & & \\
\hline & Jewellery & 3,328 \\
\hline & Electronics & 237 \\
\hline & Offical Coins (Sales) & 99 \\
\hline & Other & 226 \\
\hline Total Fabrication: & & 3,890 \\
\hline & Bar Hoarding & 337 \\
\hline & Gild Loans & 28 \\
\hline TOTAL DEMAND & & 4,255 \\
\hline
\end{tabular}

Figure 4 Gold usage in its most important applications - from Gold Fields Mineral Survey Ltd data

Figure 4 . Will the same be true in 20 years time? Certainly a wider spread of uses for gold would help to increase its price stability. Gold jewellery is the predominant commercial outlet for sales of gold. Most of the other uses for gold and its derivatives have been developed much more recently. Gold and its alloys have significant applications in dentistry and gold drugs are used for the treatment of arthritis and have potential for chemotherapy. The stability of gold means that it has found use in electrical circuitry and the recent developments in gold nanotechnology signal exciting new developments in electronics. The technologies associated with the electroforming of and electroplating with gold are well known but continue to be improved and developed, for example by using gold-matrix composite coatings.

What is addressed in the present two articles is the promise of gold catalysis, and this is one factor which may change the balance of gold demand over the next twenty years, ie a question we are evaluating is "Will gold catalysis make significant new demands for gold?" We will be considering future prospects rather than existing major applications, but I think you will agree that it is an area with significant promise for increased use of gold.

\section{HETEROGENEOUS CATALYSIS USING GOLD}

Two early reviews of gold catalysis rationalized what was thought to be the comparatively low catalytic activity of gold in many applications (5). In 1972 Bond (6) stated: "Although the catalytic properties of gold are surpassed by those of the Group VIII metals, especially palladium and platinum, possible applications of gold in catalytic processes have been widely studied". In 1985, Schwank (7) commented: "In spite of its low intrinsic activity, gold can influence the activity and selectivity of Group VIII metals". Indeed, for many years, gold was known to have poor catalytic activity in many applications, and gold systems were investigated more in the hope of boosting or modifying the known catalytic activity of other metals, including other precious metals (platinum group metals). Gold catalysts have been shown to be active for oxidation reactions, $\mathrm{eg}$ oxidation of sulfides (8) and dithioalkanes (9), dehydrogenation reactions, eg benzene formation from cyclohexene (10) isomerization, dehydrocyclization and hydrogenolysis reactions, $e g$ pentane (11), and oxidative dehydrogenation reactions (6). However, in all these applications, gold systems did not exhibit any significant catalytic advantages over other metal catalyst systems. Many of these studies involved the introduction of gold to another, more active, metal to influence the selectivity of the reaction at the expense of activity.

Recently, however, there has been a re-awakening of interest in catalysis by gold species (12), and the reactions discussed here are those where gold has been demonstrated to have potential advantages, especially increased activity or selectivity. This is prompted by recent discoveries that have shown that the observation of low catalytic activity with gold is not a universal rule, and that gold can be the catalytic metal of choice when it demonstrates the highest catalytic activity and/or selectivity. This has been demonstrated to be the case, for example in the hydrochlorination of ethyne using supported metal chlorides, and in the oxidation of carbon monoxide to carbon dioxide at ambient temperature. There are also other possibilities and, for example, in the production of hydrogen peroxide, where work to date has been predominantly with Pd-based catalysts, supported on activated carbon, it has been predicted that gold could be more active than $\mathrm{Pd}, \mathrm{Pt}$, and $\mathrm{Ag}$ (13). From a consideration of the energetics of the reactions involved, it was concluded that $\mathrm{Au}$ and $\mathrm{Ag}$ should produce the highest yields of hydrogen peroxide, and since Au has the highest activation energy for oxygen dissociation it may prove to be the best overall.

\section{Hydrochlorination of Ethyne}

The heterogeneously catalysed addition of hydrogen chloride to ethyne (acetylene) has been used for the industrial manufacture of chloroethene (vinyl chloride) (5):

$$
\mathrm{HC} \equiv \mathrm{CH}+\mathrm{HCl} \rightarrow \mathrm{CH}_{2}=\mathrm{CHCl}
$$

Supported metal chlorides have been used for this reaction, including mercuric chloride supported on 


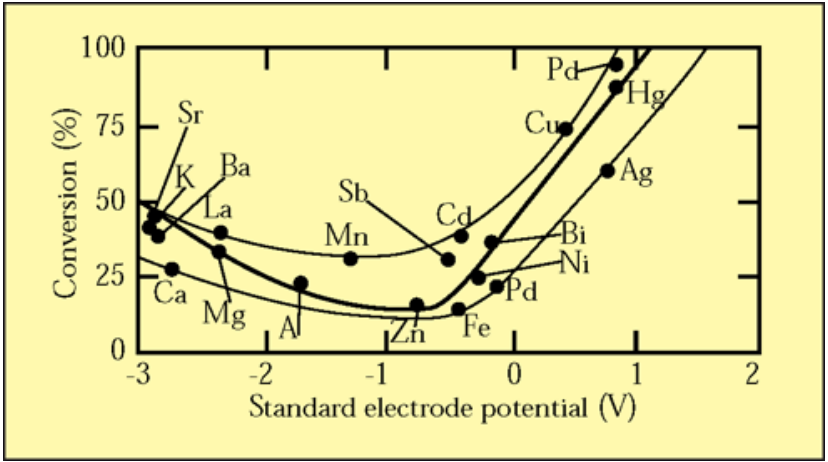

Figure 5 Correlation of hydrochlorination activity of metal chlorides supported on carbon ( $473 \mathrm{~K}$, GHSV $150 h^{-1}$ ) with standard electrode potential (based on reference 15)



Figure 6 Correlation of initial hydrochlorination activity (mol HCl mol metal $\left.^{-1} \mathrm{~h}^{-1}\right)$ of metal chlorides supported on carbon ( $453 \mathrm{~K}$, GHSV $\left.1140 \mathrm{~h}^{-1}\right)$ with standard electrode potential. Catalysts contained $5 \times 10^{-4} \mathrm{~mol}$ metal / $100 \mathrm{~g}$ catalyst (based on reference 18)

carbon which has been used industrially. Mercuric chloride catalysts deactivate quite rapidly under reaction conditions and, in view of the toxicity of these catalysts, there have been a number of studies on the use of alternative catalysts.

\section{Prediction of the Enhanced Activity of Gold Catalysts}

In the previous studies, carbon was found to be the preferred support since when silica was used some polymerization products were observed. Further studies indicated that the rate-determining step involves the additibn of $\mathrm{HCl}$ to a surface ethyne complex (5):

$$
\mathrm{MCl}_{\mathrm{n}}+\mathrm{HC} \equiv \mathrm{CH}+\mathrm{HCl} \rightarrow \mathrm{MCl}_{\mathrm{n}} \cdot \mathrm{HC} \equiv \mathrm{CH} \cdot \mathrm{HCl}
$$

Active catalysts should therefore be able to form surface metal-ethyne and metal $\mathrm{HCl}$ complexes. Metastable acetylides are known for many metals including: $\mathrm{Cu}, \mathrm{Ag}, \mathrm{Au}, \mathrm{Na}, \mathrm{K}, \mathrm{Rb}, \mathrm{Zn}, \mathrm{Cd}, \mathrm{Hg}, \mathrm{Pd}$, Os, $\mathrm{Ce}, \mathrm{Al}, \mathrm{Mg}, \mathrm{Ca}, \mathrm{Sr}, \mathrm{Ba}$ and are considered possible for $\mathrm{Pt}, \mathrm{Ru}, \mathrm{Rh}$, Ir. The stability of these acetylides can be expected to be an important parameter in controlling the activity of these metals and their salts. From a study of a range of metal chlorides, the activity could be correlated with the electron affinity of the cation. However, one of the most extensive studies of metal chloride catalysts was carried out by Shinoda (14) and with more data the simple correlation with electron affinity was no longer valid. Shinoda considered that a correlation existed with the electron affinity divided by the metal valence (oxidation state).

Hutchings proposed (15) that the standard electrode potential should be a more suitable parameter for the correlation of catalytic activity and the correlation is shown in Figure 5. The data fall on a smooth curve and can be satisfactorily represented by a single function. The importance of this, is that this correlation can be used predictively, since any metal cation with a higher electrode potential than $\mathrm{Hg}^{2+}$ would be expected to give enhanced catalytic activity. On this basis gold cations would be predicted to be the most active catalysts for this reaction. Subsequent research (16) confirmed this prediction (Figure 6) and on an initial rate basis gold catalysts are about three times more active than mercuric chloride catalysts. This was the first example of a reaction for which a gold catalyst was found to exhibit the highest activity.

\section{Hydrochlorination of Ethyne using Gold Catalyst Systems}

Active gold-containing catalysts were prepared by impregnation by chloroauric acid solutions onto activated carbon and the best results were obtained if the chloroauric acid was dissolved in aqua regia. One unfortunate observation for all metal chloride catalysts for this reaction is that they deactivate with time on stream when used in a standard fixed bed reactor. However, gold catalyst systems have a lower rate of deactivation than would be expected (Figure 7). Furthermore, the rate of deactivation is significantly decreased for higher gold loadings, although the lowest gold loadings give the highest initial reaction rate. Surprisingly, the deactivation rate is very temperature dependent and high rates of deactivation are observed at both high and low temperatures. The low temperature deactivation is due to coke deposition, probably as a result of surface polymerization reactions of chloroethene and ethyne. The highest reaction rates 


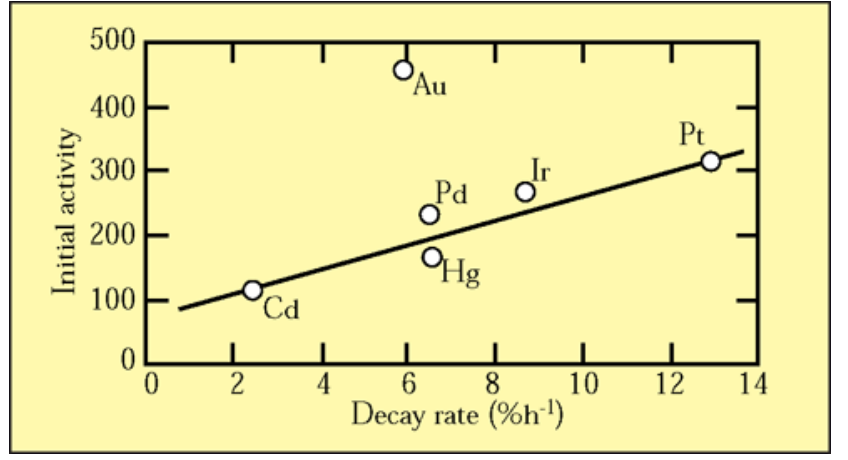

Figure 7 Correlation between initial catalyst activity and conversion decay rate (average loss of conversion (\%) for the initial 3 h reaction). Catalysts contained $5 \times 10^{4} \mathrm{~mol}$ metal/100g catalyst (based on reference 18)

are observed at $453 \mathrm{~K}$, and the cause of the deactivation at this temperature was elucidated using ${ }^{197} \mathrm{Au}$ Mossbauer spectroscopy, which gave the relative concentrations of $\mathrm{Au}(\mathrm{O}), \mathrm{Au}(\mathrm{I})$ and $\mathrm{Au}(\mathrm{III})$ present in the catalysts. These studies confirmed that deactivation at the higher temperature was due to reduction of $\mathrm{Au}$ (III) to metallic gold (5). In addition, $\mathrm{Au}(\mathrm{I})$ was also observed to be present in these catalysts. Studies using catalysts containing only $\mathrm{Au}(0), \mathrm{Au}(\mathrm{I})$ and both $\mathrm{Au}(\mathrm{III})$ and $\mathrm{Au}(0)$ (it was not possible to prepare catalysts containing only $\mathrm{Au}(\mathrm{III}))$ showed that the rate of reaction decreased in the order $\mathrm{Au}(\mathrm{III})>\mathrm{Au}(\mathrm{I})>\mathrm{Au}(0)$.

Deactivation is a common operational problem for heterogeneous catalysts and therefore it is important to devise a strategy for reactivation so that the catalyst can be continued to be used. In the studies with mercuric chloride catalysts it was found that some activity could be restored with an off-line treatment of the catalyst with hydrogen chloride at $>453 \mathrm{~K}(5)$. However, a principle cause for activity loss was found to be loss of mercuric chloride from the catalyst during use (17). This is not the case for the gold catalyst since under the reaction conditions employed no gold is lost and deactivation is mainly due to reduction of both $\mathrm{Au}$ (III) and $\mathrm{Au}(\mathrm{I})$ to $\mathrm{Au}(0)(18)$. For gold catalysts, off-line hydrogen chloride treatment of the catalyst at $>453 \mathrm{~K}$ did restore some activity but, as such a treatment could not oxidize the elemental gold, full activity was not restored. Treatments of the deactivated catalyst off-line with chlorine, nitric oxide and nitrous oxide at elevated temperatures $(>453 \mathrm{~K})$ were effective and the best results were obtained using nitric oxide. However, the most significant observation was that nitric oxide could be fed together with the reactants, and deactivation was virtually eliminated, and there was no effect on chloroethene selectivity (19). In this way the gold catalysts can be used for extended reaction periods. This represents a very interesting example of on-line reactivation and may be applicable to other gold catalysis applications.

\section{Low Temperature Oxidation of Carbon Monoxide}

The oxidation of carbon monoxide at ambient temperature is a very important reaction for air purification systems and breathing apparatus. The industrial catalyst used at present is hopcalite (5) which is a mixed oxide of copper and manganese, $\mathrm{CuMn}_{2} \mathrm{O}_{3}$, but this catalyst deactivates quite rapidly and is unsuitable for long term use. Certain applications require the catalyst to survive and remain effective for many weeks, $e g$ in the purification of air in long duration space travel. There is another reason for the intense interest in low temperature carbon monoxide oxidation and this concerns the low temperature performance of car exhaust catalysts. On start-up car exhaust catalysts can take a little time to become effective, and this is mainly due to the time required to heat the catalyst using the exothermicity of the combustion reactions. If a catalyst component could be incorporated that is effective for combustion at lower temperatures, then this initial warm-up period could be shortened.

\section{Carbon Monoxide Oxidation Using Gold Catalysts}

Haruta et al $(20,21)$ were the first to show that gold catalysts could be effective at ambient temperature. He noted that gold catalysts prepared using a conventional impregnation procedure were considerably less active than platinum group metals catalysts prepared in a similar way. It is probably for this reason that gold was then overlooked by many researchers as an oxidation catalyst (5). Haruta showed that the method of catalyst preparation is very important and that if a coprecipitation procedure is used, high activity catalysts are obtained. The catalysts were prepared from addition of an aqueous solution of chloroauric acid and a metal nitrate to an aqueous sodium carbonate solution. The precipitate was then washed, vacuum dried and calcined at $673 \mathrm{~K}$. In addition, Haruta et al (22) have also shown that catalysts can be prepared using deposition precipitation. Haruta evaluated a range of metal oxide supports (Figure 8) and observed that the best results were obtained with $\alpha-\mathrm{Fe}_{2} \mathrm{O}_{3}$, with a gold loading of $5 \%$.

Haruta observed that this catalyst was even effective at sub-ambient temperatures and activity was 


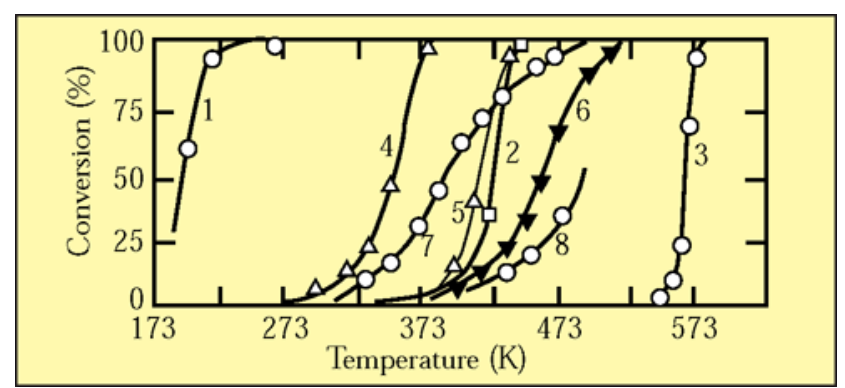

Figure 8 Oxidation efficiencies for carbon monoxide oxidation for $\mathrm{Au} / \alpha-\mathrm{Fe}_{2} \mathrm{O}_{3}$ in relation to catalyst temperature in comparison with other catalysts. $1 \mathrm{Au} \alpha \mathrm{\alpha}-\mathrm{Fe}_{2} \mathrm{O}_{3}(\mathrm{Au} / \mathrm{Fe}$ =1:19), prepared by co-precipitation; 20.5 wt\% $\mathrm{Pd} \gamma-\mathrm{Al}_{2} \mathrm{O}_{3}$, prepared by impregnation; 3 gold fine powder; $4 \mathrm{Co}_{3} \mathrm{O}_{4}$ ex-carbonate; $5 \mathrm{NiO} ; 6 \alpha-\mathrm{Fe}_{2} \mathrm{O}_{3}$. $75 \mathrm{w} \% \mathrm{Au} / \mathrm{\alpha}-\mathrm{Fe}_{2} \mathrm{O}_{3}$, prepared by impregnation; $85 \mathrm{wt} \% \mathrm{Au} \gamma-\mathrm{Al}_{2} \mathrm{O}_{3}$, prepared by impregnation (based on reference 21)

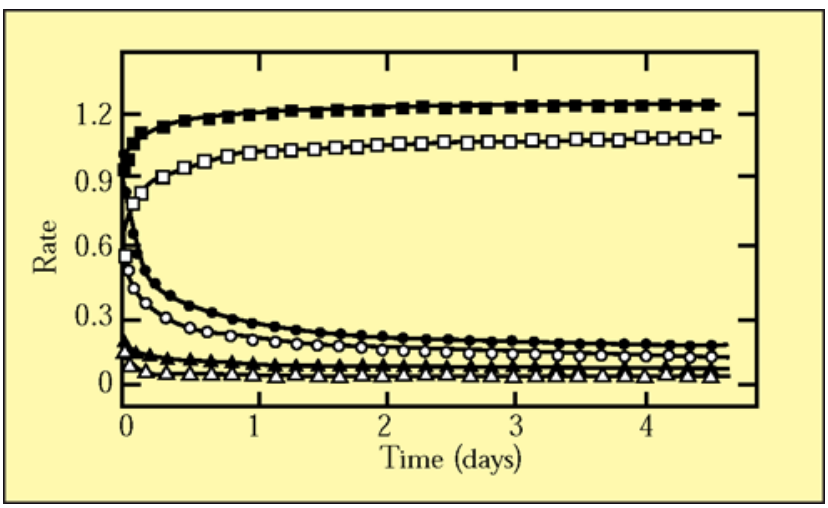

Figure 9 The carbon monoxide oxidation activity found for 10 at\% $\mathrm{Au} / \mathrm{MnO}_{x}(\mathbf{\square}, \mathbf{\square}), 19.5$ wt\% $\mathrm{Pt}_{t} \mathrm{SnO}_{x}(\mathbf{0}, \mathbf{0})$, and 2 wt $\% \mathrm{Pt} / \mathrm{S}_{n} \mathrm{O}_{x}(\mathbf{\Delta}, \mathbf{\Delta})$ at $328 \mathrm{~K}$ without pretreatment (open symbols) and pretreatment in 5 vol\% carbon monoxide/helium at $323 \mathrm{~K}$ (solid symbols). Rates are expressed in $\mathrm{mol}(\mathrm{g} \text { cat })^{-1} \mathrm{~s}^{-1} \mathrm{X}$ $10^{-6}$. Under the conditions of these experiments a rate of $1.5 \times 10^{-6}$ corresponds to $100 \%$ conversion (based on reference 25)

observed at temperatures as low as $197 \mathrm{~K}$. However, except for a few reports of activity being observed at these low temperatures, recent research papers have concentrated on the use of ambient temperatures or temperatures up to $353 \mathrm{~K}$. The detailed work of Haruta has led to an understanding of the improved catalytic activity of the co-precipitated catalysts. He has found that this method results in a very uniform dispersion of small metallic gold particles on the support. The best results are obtained when these particles are ca $5 \mathrm{~nm}$ or less in diameter $(23,24)$ and when reaction temperatures of $>328 \mathrm{~K}$ are used. Iron oxide is not a commonly used catalyst support for other precious metals and the optimum crystallite size is larger ( $c a 2-5 \mathrm{~nm}$ ) for gold than for many other precious metal systems. The reasons for these differences should be further investigated in order to throw more light on how the gold systems work - this could lead to optimization of their use, ie improving the activities so far obtained.

Studies by Gardner et al (25) confirmed the high activity of gold catalysts and, in particular, contrasted the high activity gold catalysts with a supported platinum catalyst. They showed that the gold catalysts were more active than the platinum catalyst by a factor of five (Figure 9).

One of the main problems for supported gold catalysts for this reaction is deactivation. All Au/metal oxide catalysts deactivate during carbon monoxide oxidation, and particularly when carbon dioxide is present in the feed. This is of course a major problem for breathing air applications, since significant carbon dioxide concentrations are present (26).

Hutchings et al (5) have studied the problem of deactivation using their knowledge of the effect of ageing of catalyst precipitation precursors in solution on the eventual catalyst performance for copper-based catalysts. $\mathrm{Au} / \mathrm{CuO} / \mathrm{ZnO}, \mathrm{Au} / \mathrm{ZnO}$ and the $\mathrm{Au} / \mathrm{CuO}$ catalysts were prepared using a co-precipitation method in which the initial precipitate is stirred, ie aged, in the solution for $180 \mathrm{~min}$ prior to recovery and washing. These catalysts were found to give sustained activity without deactivation during the $800 \mathrm{~min}$ experimental test (Figure 10). The non- Au-containing $\mathrm{CuO} / \mathrm{ZnO}$ catalyst prepared using the same coprecipitation procedure displays a much lower activity and a general decline in carbon monoxide conversion together with oscillations in catalytic activity. Such phenomena had been noted previously for non-Aucontaining catalysts for this reaction (27). Examination of the catalysts by electron microscopy showed that no morphological differences were observed between any particular used catalyst and its unused counterpart. A common characteristic of all the catalysts is the presence of discrete gold particles which frequently exhibit multiple twinning. There is, however, a distinct difference in the sizes and dispersion of the gold particles in these different catalysts. The best performance was obtained with the $\mathrm{Au} / \mathrm{ZnO}$ catalyst in which much smaller gold particles (mean particle size is ca $2-5 \mathrm{~nm}$ ) are supported on feathery zinccontaining crystallites.

The method of co-precipitation used is important 


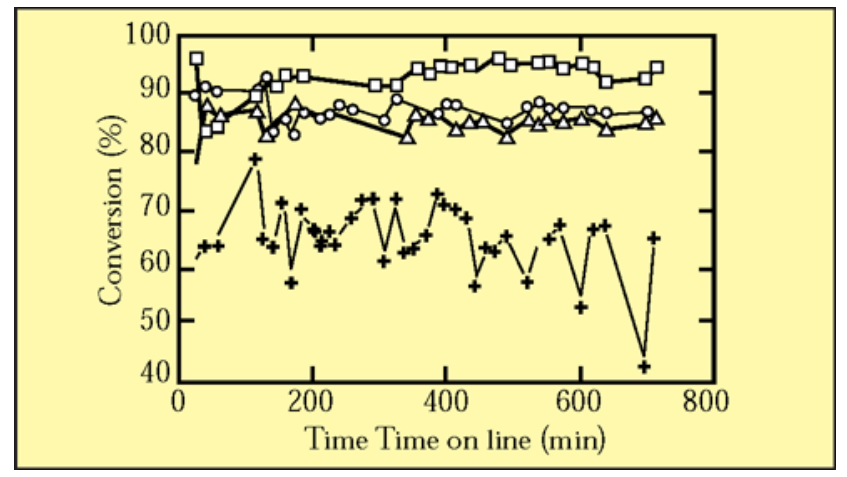

Figure 10 Catalytic performance for carbon monoxide oxidation at $293 \mathrm{~K}(0.45 \% \mathrm{CO}, \mathrm{GHSV}=33,000$ $\left.h^{-1}\right)$ for $A u / Z n O(\square) ; A u / C u O(\mathbf{O}) ; A u / C u O / Z n O$ $(\triangle)$; and $\mathrm{CuO} / \mathrm{ZnO}(+)$ (aged $300 \mathrm{~min}$ ) (based on reference 5)

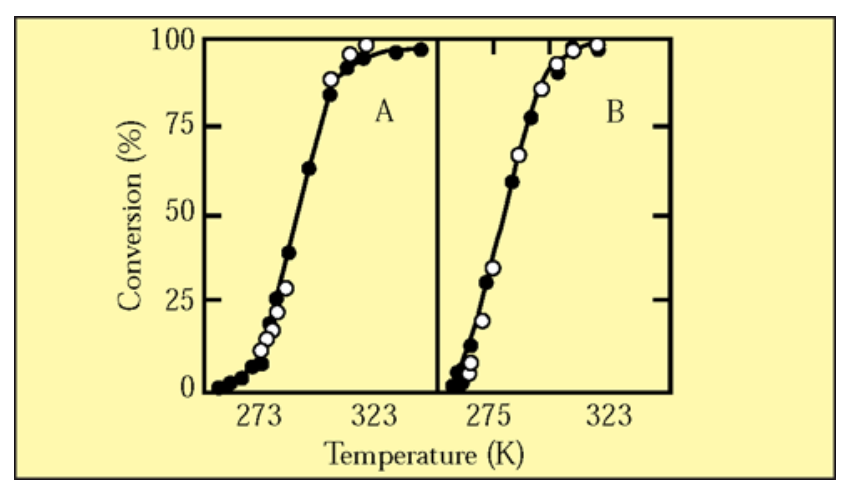

Figure 11 Conversion efficiency for catalysts derived from $A u_{5} \mathrm{Ag}_{5} \mathrm{r}_{14}$ (A) and $\mathrm{Au} \mathrm{u}_{5} \mathrm{Fe}_{\mathrm{H}} \mathrm{r}_{14}$ (B) measured for ascending (filled circles) and descending (open circles) temperature. Each point represents carbon monoxide conversion after steady state was achieved (based on reference 30)

for the attainment of the sustained high activity catalysts. In the earlier work by Haruta et al $(21,28)$, the catalysts were prepared using a precipitation method in which the precipitate was not aged in the solution, ie the precipitate was recovered immediately after the precipitation step rather than allowing it to remain in contact with the precipitating solution for an extended time period. Earlier studies had shown that the ageing of the $\mathrm{CuO} / \mathrm{ZnO}$ precipitate could be crucial with respect to the formation of an active catalyst for the hydrogenation of carbon monoxide to methanol and in general the preferred catalysts are produced from a precursor that has been aged for at least $180 \mathrm{~min}$ (29). When gold is present in the coprecipitation mixture the initial precipitate that forms is amorphous. During the ageing process the precipitate gradually crystallizes. The sustained high activity of these catalysts was evident in that the carbon monoxide conversion for the $2 \% \mathrm{Au} / \mathrm{ZnO}$ catalyst was typically $>90 \%$ over the test period and the rate of carbon monoxide oxidation was typically $6 \mathrm{~mol} / \mathrm{kg}$ catalyst/h. Although the previously cited gold catalysts, prepared by co-precipitation without an ageing step, generally gave initial carbon monoxide conversions that were equivalent, they were known to deactivate rapidly at $293 \mathrm{~K}$ and half lives of only 100-200 min were observed. These results (5) were not optimized but they were indicative of the improved catalytic performance that can be achieved using a method of preparation that is a combination of the $\mathrm{Co}^{-}$ precipitation procedure together with controlled ageing of the precipitate.

A more traditional approach to gold alloy catalyst preparation (30) gave systems which are highly active for carbon monoxide oxidation at around ambient temperatures (Figure 11). Amorphous metal alloys with the compositions (at\%) $\mathrm{Au}_{5} \mathrm{FeZr}_{14}$ and Aus $\mathrm{AgZr}_{14}$ were used as precursors for the preparation of gold/zirconia/iron oxide and gold/silver/zirconia catalysts for low temperature oxidation of carbon monoxide. The catalysts were prepared by in situ activation (oxidation) of the glassy metal alloys under carbon monoxide oxidation conditions at $553 \mathrm{~K}$. Kinetic tests performed in a continuous tubular microreactor in the temperature range from 253 to $323 \mathrm{~K}$ showed that both catalysts are highly active for the oxidation of carbon monoxide at low temperatures. Carbon monoxide oxidation rates increased considerably if the $\mathrm{CO}: \mathrm{O}_{2}$ ratio in the reactant feed was changed from stoichiometry $(2: 1)$ to conditions of excess oxygen $(1: 2)$.

\section{CONCLUSIONS}

We can conclude from the work described in this article that supported gold catalysts are the most active for the hydrochlorination of acetylene (ethyne), and that $\mathrm{Au} / \mathrm{Fe}_{2} \mathrm{O}_{3}$ is the best catalyst found to date for the oxidation of carbon monoxide at low temperatures. The control of gold particle size to between about two and four to five nanometres is important (31) and this can be achieved using deposition precipitation or co-precipitation techniques.

In Part II of this pair of articles we will consider other heterogeneous reactions catalysed by gold including catalytic combustion of hydrocarbons, selective oxidation, hydrogenation of carbon oxides, the reduction of nitrogen oxides with propene, carbon 
monoxide or hydrogen, and the oxidative decomposition of halogen compounds. We will also consider reactions catalysed by homogeneous and supported homogeneous gold systems.

Present indications are that catalysis by gold is distinctly different from catalysis using other precious metals, ie some aspects are unique. Although these are early days, there are a number of areas where gold catalysis has industrial potential. In-depth study of these areas is likely to lead to a better understanding of the effects so far recorded and to provide the basis for new applications in chemical processing and pollution control. An increased spectrum of uses for gold would help to stabilize its price. On the basis of what has happened to platinum sales over the last 20 years it is reasonable to speculate that a significant proportion of gold sales could soon begin to increase outside traditional areas.

\section{ACKNOWLEDGEMENTS}

The author is grateful for supply of information by $\mathrm{Dr}$ Masatake Haruta (Osaka National Research Institute, Japan) and for helpful discussions with Professors Geoffrey Bond (Brunel University, Uxbridge, UK) and Graham Hutchings (Cardiff University, UK); parts of this article rely heavily on the review by Professor Hutchings entitled 'Catalysis: A Golden Future' and published previously in Gold Bulletin (1998, 29, 123). Figures 2 and 5-11 were re-drawn from the original literature during preparation for a review article entitled 'Catalysis by Gold' by G.C. Bond and D.T.Thompson and recently accepted for publication in Catalysis Reviews - Science and Engineering. Thanks are also due to Dr Lucy Thompson for literature searches and to the IMPI for permission to publish the whole of the Toronto talk (see footnote to p. 111).

\section{ABOUT THE AUTHOR}

David Thompson has participated in and managed upstream, basic and applied research activities in universities (Imperial College, London and University of California, Los Angeles), ICI, and Johnson Matthey. His published papers are concerned with catalysis and materials topics, particularly those involved with precious metals, as well as with organic and inorganic chemistry. He is Technical Editor of Gold Bulletin and Consultant to World Gold Council. In his freelance work as a chemical consultant he advises on catalyst system design for chemical processing, pollution control and gas detection. Some of this work is carried out in collaboration with universities, and he helps industrial organizations to optimize their contacts with university research. He has contributed to and assisted in the editing of a new book to be published in 1999 entitled 'The Company of the Future'.

\section{REFERENCES}

1 H. Schmidbaur, Gold Bull, 1990, 23, 11

2 P. Pyykko, Chem. Rev, 1988, 88, 563

3 P. Pyykko, J. Am. Chem. Soc, 1995, 117, 2067

4 P. Schwerdtfeger, Angew Chem, 1996, 108, 2973

5 G.J. Hutchings, Gold Bull., 1996, 29, 123

6 G.C. Bond Gold Bull., 1972, 5, 11

7 J. Schwank, Gold Bull, 1985, 18, 2; see also Gold Bull., 1983, 16, 103

8 F. Gasparrini, M. Giovannoli, D. Misiti, G. Natile and G. Palmierri, Tetrahedron, 1983, 39, 3181

9 F. Gasparrini, M. Giovannoli, D. Misiti, G. Natile and G. Palmierri, Tetrahedron, 1984, 40,165

10 J.W.A. Schachtler, M.A. Van Hove, J.P. Biberian and G.A. Somorjai, Phys. Rev. Lett., $1980,45,1601$

11 J.R.H. Schaik, R.P. Dressing and V. Ponec, J. Catal.,1975, 38, 273

12 D. Thompson, Gold Bull, 1996, 29,94

13 P.P. Olivera, E.M. Patrito and H. Sellars, Surf. Sci., 1994, 313, 25

14 K. Shinoda, Chem. Lett., 1975, 219

15 G.J. Hutchings, J. Catal., 1985, 96, 292

16 B. Nkosi, N.J. Coville and G.J. Hutchings, J. Chem. Soc, Chem. Commum, 1988, 71; Appl. Catal., 1988, 43, 33

17 G.J. Hutchings and D. Grady, Appl. Catal, 1985, 16, 441; 1985, 17, 155

18 B. Nkosi, N.J. Coville, G.J. Hutchings, M.D. Adams, J. Friedl and F. Wagner, J. Catal, $1991, \mathbf{1 2 8}, 366$

19 B. Nkosi, M.D. Adams, N.J. Coville and G.J. Hutchings, J. Catal, 1991, 128, 378

20 M. Haruta, T. Kobayashi, H. Sano and N. Yamada, Chem. Lett, 1987, 405

21 M. Haruta, N. Yamada, T. Kobayashi and S. Ijima, J. Catal., 1989, 115, 301

22 M. Haruta, S. Tsubota, T. Kobayashi, H. Kageyama, M.J. Genet and B. Delmon, J. Catal., 1993, 144, 175

23 M. Haruta, A. Ueda, R.M. Torres Sanchez and K. Tanaka, Prp. Pet. Div, ACS Symp., New Orleans, 1996

24 T. Hayashi, K. Tanaka and M. Haruta, Prp. Pet. Div, ACS Symp., New Orleans, 1996

25 S.D. Gardner, G.B. Hoflund, B.T. Upchurch, D.R. Schryer, E.J. Kielen and J. Schryer, J. Catal., 1991, 129, 114

26 G. Srinivas, J Wright, C-S. Bai and R. Cook, Stud. Surf. Sci. Catal, 1996, 101, 427

27 F. Bocuzzi, A. Chirorini, S. Tsubota and M. Haruta, Catal. Lett., 1994, 29, 225

28 G.J. Hutchings, M.R.H. Siddiqui, A. Burrows, C.J. Keily and R. Whyman, J. Chem. Soc., Faraday Trans., 1997, 93, 187

29 R.W. Joyner, F. King, M.A. Thomas and G. Roberts, Catal. Today, 1991, 10, 417

30 A. Baiker, M. Maciejewski, S. Tagliaferri and P. Hug, J. Catal, 1995, 151, 407

31 M. Valden, X. Lai and D.W. Goodman, Science, 1998, 281, 1647 